\title{
IDENTITY AND DIGNITY IN NARRATIVE BIOGRAPHICAL EPISODES OF CONTEMPORARY POLISH 'NON-MIGRANTS'
}

\author{
by Rozalia Ligus
}

\section{Theoretical and Methodological Position, Project Participants and Empirical Material}

The results presented in the paper comprise the outcome of five projects carried out in the years 2000-2012. The inspiration for the preparation of a comparative analysis and 'going across' the acquired data was the similarity between the semantic categories 'extracted' from each subsequent portion of the material collected in the selected projects. This led to the formation of a collective, qualitative case study in the sense coined by Robert Stake (2005), in which I set the goal of monitoring the process of redefining the meaning that the narrators (affected indirectly or directly by contemporary migration processes) attribute to identity and dignity. Both these categories are the result of the analyses and interpretation of the gathered empirical material, and not concepts imposed a priori. They are also hulled from the entire collection of meanings assigned by the interlocutors to the experiences of their life and their selected "biographical episodes." ${ }^{1}$

1 'Biographical episode' is a term used by modern methodologists (N. Denzin, I. Helling, K. Konecki, F. Schütze and others). I use the definition of Piotr Jaksa Bykowski who applied this term in his Dwór Królewski w Grodnie: Epizod biograficzny 1795-1797 (The Royal Court in Grodno: Biographical episode 1795-1797), published in 1884, considering that it describes best the work that is an analysis and interpretation of the selected set of documents on the last visit of King Stanislaus Augustus and his court in Grodno. In the opinion of Bykowski, the term 'biographical episode' determines the publication content more accurately than usurping the right to call it 'history,' since the knowledge of the author was fragmentary 
Thanks to a vast collection of categories proposed by the project participants, the analysis of the input material allowed me to build a continuum of meanings (conditions), indicated by them as crucial in the process of redefining their identity inextricably interwoven with a sense of dignity. This continuum is going to be presented at the end of this text. The starting point for the construction of the continuum of meanings that constitute personal identity in the context of migration was the concept of the "universe of obligation" by Helen Fein (Fein, 1995; Gamson, 1996), rooted in ancient history of the Jews (Gamson, 1996) and characterized by the process of social inclusion/exclusion.

The theoretical justification for the empirical material presented here is the idea of the modern identity of Charles Taylor (1994a, 1994b), Ricoeur's concept of recognition, the need of being socially recognized and accepted (Ricoeur, 2005) and Habermas's concept of a dialogue (Habermas, 2003). I also use the postmodern worldview characterized by Zygmunt Bauman (2000) and the above-mentioned concept of the universe of obligation proposed by Helen Fein (1995).

All five projects were implemented in line with the qualitative approach and interpretive paradigm. In case of four of them, the applied method of gathering empirical material was that of a narrative interview. One of the projects was expanded to embrace biographical interviews, ${ }^{2}$ and another one was used to collect empirical material in the form of anonymous statements, namely one-page letters sent by e-mail. The participants represented four generations (the oldest were over 70 years old, the youngest were in their twenties). Only nine out of 32 narrators interviewed by me

and composed from a variety of sources collected by other authors. By analogy, I collected narrative interviews and letters that provide a description of biographical episodes selected by the authors, which they considered important in the process of redefining their identity.

The term 'biographical narrative interview' is used referring to the method of F. Schütze, popularized in Poland by Marek Czyżewski, Kaja Kaźmierska, Danuta Urbaniak-Zając, Jacek Piekarski and the author himself. The analysis and interpretation cover the story of life told by the narrator, which reveals his/her unique, personal vision and understanding of the world. There appear 'facts' qualitatively different from those that in the standard way refer to the socio-cultural knowledge of the narrators. In the Anglo-Saxon tradition of methodology, a lot of attention is paid to distinguishing narrative interviews from biographical narrative interviews. For example, Donald E. Polkinghorne (2005/1995, p. 21) suggests two types of narrative inquiry- "the paradigmatic type" and "the narrative type." Polkinghorne justifies this proposal claiming that, despite the fact that each of these types is related to collecting stories, they differ qualitatively-in the paradigmatic approach we simply collect data and the narrative type is aimed at gathering accounts of events, adventures and activities, in which the narrator participates. The result of a paradigmatic analysis may be new categories and concepts, and in the case of the narrative inquiry we focus on the creation of knowledge relating to a specific, individual situation. 
lived abroad (outside Poland) and took on the status of 'migrants.' The overall empirical material includes 32 narrative interviews and 170 letters describing the experience of 'being involved' in the migration processes directly or indirectly. The general research question was: 'What meanings are given by the narrators to their experiences while interpreting their being incorporated in the migration processes (in a direct or indirect way)?'

\section{Inspiration to Undertake Research on Migration-Permeability of the Worlds of the Researcher and the Narrator}

The presented article makes a window of opportunity to 'reveal' my personal path that I followed as a researcher, engaging in the accumulation of further empirical material, often at the urge of the narrators-participants in my research. It was them who skillfully 'guided' my attention to the issue, which I previously had not connected directly to the research objectives.

This was the case of the research carried out by me in the years 2000-2004, the aim of which was to investigate the course of professional development of teachers and their career. The objectives and the questions raised in this pedeutologically rooted project were far from considerations upon migration processes. Then, in 2000, that is four years before Poland joined other Member States in the European Union, I was interested in teachers' 'here and now.' Meanwhile, my narrators demanded of me understanding their generational experience and recognition of their identity as a weave of their own experiences in relation with the events regarding their ancestors (parents, grandparents, great-grandparents), and they made the category of migration the center of constituting their identity. Shelley Jackson (2009) calls it a "patchwork identity," which consists in using the history of the family members to identify with their experiences and the constitution in this way of one's own identity. ${ }^{3}$ Paul Ricoeur talks in turn about "self-identity" (Ricoeur, 2005, p. 104) and the "genealogical method" (ibid., p. 152), forming our source identity.

Since my first major research, prepared for my Ph.D. thesis, more than ten years have elapsed, and I keep coming back to the experience of 'removing the cataract from the researcher's eyes,' which I owe to my project participants. They inspired me to expand my field of research and include in it the problem of migration, which at first was quite surprising for me.

As it turned out, both the pedeutological issues that I was dealing with and also the choice of the study area proved to be significant. Conducting

3 Shelley Jackson (born in 1963) is a contemporary American writer dealing with the socalled hyperfiction. In one of her most popular novels, Patchwork Girl (1995), drafted in the convention of a hypertext, she writes about constituting one's identity by identifying with the stories of relatives. 
the research in the north-west Polish border region (burdened with the history of the post-war frontier changes and resettlement) enabled me to bring to light the specifics of the socio-cultural context in which the careers of the teachers working there were formed, but also, even more importantly, their biographical identity (Ligus, 2009).

Now I know that my first major research project became a turning point in building my understanding of the social implications of migration processes and their importance to the quality of social life. It showed me as well how essential it is to follow the voice of the narrators who extend the originally outlined area of interest and enrich the researcher not only with new knowledge, but also through sharpening his/her sensitivity towards the fresh, overlooked aspects of the issues that such researcher is dealing with.

I would like to return for a moment to the category of migration distinguished in the course of these studies and emphasize a fact that I found thoroughly astounding. The collected biographical narrative interviews revealed that being incorporated in the migration processes, even only in an indirect way (for example, as a child of immigrants), we become the 'heirs' of the experience. Many of the participants in this study were born in the 1960s and 1970s and did not suffer the trauma related to the resettlement, the "eradication" or "cutting off the roots" (Kaźmierska, 1999, pp. 180-192), and yet their narratives provide plenty of motifs that relate to the experience of earlier generations as well as family genealogy and make a crucial element in the constitution of one's own biographical identity (Ligus, 2009; 2011a; b).

This experience of a young researcher who-asking the question about the quality and nature of teachers' work-is given the task of reconstructing the history of life of their ancestors even up to the third generation, triggered in me a lot of thought over dimensionality and the phenomenon of migration, which after all is inscribed in the daily life of the modern world and, in a sense, has touched all of us (since Stephen Castles and Mark J. Miller announced that the twenty-first century will be "the age of migration" (Castels \& Miller, 1993) we have had no other option but to enter this category into the social everyday life). In fact, since that experience I have not thought about migration as a sociological phenomenon, ${ }^{4}$ but it has assumed for me the psycho-cultural, anthropological importance embedded deep in the human experience and collective memory (Halbwachs, 1992). Soon after it, what became clear was the fact that the political and economic changes taking place in Poland after the accession

4 The modern definition of the word 'migration' still evokes the traditional meaning of the term 'migrant' as "a person or animal that moves from one region, place, or country to another" (Collins..., entry: migrant). It is against this sense of the word that young people are protesting today, even if they leave the country for economic reasons. 
to the European Union, finalized in 2004, have generated further migration processes that have left their mark on every aspect of our lives, be it the socio-economic or cultural aspect (Kozak, 2010, pp. 112-162). And so, following the traces of migration as one of the dimensions of the experience of modern man, I commenced my consecutive research projects.

The migration wave counting nearly two million people that spilled out from Poland after 2004 reaching the British Isles and swiping over every country in Western Europe on its way, left a mark on the families and close friends of Polish 'migrants.' Although these people remained in the country (Ligus, 2011a), they were involved in the migration processes through a personal relationship with the 'migrants.' This situation has also shown the outdated nature of the vocabulary describing the contemporary phenomena of migration and the fact that we need a new kit of concepts, which would be adequate to circumscribe the feelings and experiences of young, mobile Poles and other EU citizens. For now, we resort to the metaphorical expressions coined by Zygmunt Bauman (2000), such as "tourists" and "vagabonds," because young Poles living abroad do not agree to being called 'migrants' (Ligus, 2011). They say they are the "citizens of the world" (Ligus, 2011a; b).

My first research made me realize that the experience of migration, just as stigmatization, is transferred to the persons closest to the 'migrants.' Erving Goffman (1963) refers to this phenomenon as "passing the sigma."

Justifying the sense of the comparative analyses undertaken by me, regarding the results of the selected projects, I want to draw attention to the oddity that I found in the utterances of all study subjects. Regardless of their age and the time their experiences came from, the categories the narrators pointed to were characterized by amazing likeness. No matter whether I interviewed practicing teachers about the experiences related to their current work, or people living abroad or their families about issues of great concern to them, I received similar responses. Therefore, the results of the research made me think that one of the forces of migration is the provocative role to re-pose questions about the source of one's own identity, but also about new constructs required for its re-constitution. Migration, like a pebble breaking a smooth surface of the lake, produces countless rings radiating and resulting in successive waves that picture the involvement of consecutive generations.

In conclusion, I can say that the inspiration to carry out a comparative analysis of the experiences of people entangled in different aspects of migration was, on the one hand, the obtained research results and my personal experience of the researcher derived from each subsequent project, in which the narrators pointed to the categories meaningful for them-e.g. 
experiencing migration. On the other hand, my interest in migration issues was launched by its pervasive presence, which led to the socio-cultural and political changes that directly translate into everyday life. The balance of these events generated my own questions of methodological and ethical nature. What kind of obligation does a researcher impose on himself/herself while conducting narrative interviews, including the biographical ones? Are we, as biographical researchers, actually sensitive to the voice of our narrators? Do we open to their message, or maybe 'we take' from the interview what we came for abandoning them 'half-way'? How should we deal with the themes 'neglected' or temporarily 'deserted' by us-researchers?

Due to the course of my present considerations, I will refrain here from the development of those vital questions, leaving their analysis for another occasion.

\section{Dignity and Identity Redefined in Biographical Episodes: Selected Pieces of Analyses and Interpretation}

The decisive characteristic that induced me to take up a deeper analysis of the meanings ascribed to the experience of narrators involved in migration processes (the post-war and contemporary ones) was the reproducibility of the categories indicated by the participants taking the form of values, characteristics and conditions, which constitute for them an inherent aspect of their life in dignity.

The extraction and compilation of these categories led to the creation of a matrix (Table 1) comprising the propositions of the narrators. The categories are placed horizontally so as to make it easy to see their reproducibility in the sequentially undertaken projects. Vertical columns indicate the time frame of the research and the number of participants and provide an overview of the objectives of the research tasks. In the vertical layout of the categories, I adopted the alphabetical order which facilitates locating and reviewing them. The extraction of categories such as: acceptance, authenticity, humanity, appreciation, respect, independence, self-direction, dignity (which narrators explicitly refer to in their statements), freedom, sensitivity to other cultures, forced me to pose 'immanent questions ${ }^{5}$ concerning the message hidden in these categories.

5 The term 'immanent questions' is related to the biographical method of F. Schütze. It defines the kind of questions asked by the investigator usually after the 'first story' of the narrator. They directly result from the narrator's story, go deep into his/her history, inquire about what still needs to be specified following the initial research meeting (cf. Schütze, 1983). 
Table 1. Matrix of categories derived from the analyses and interpretations

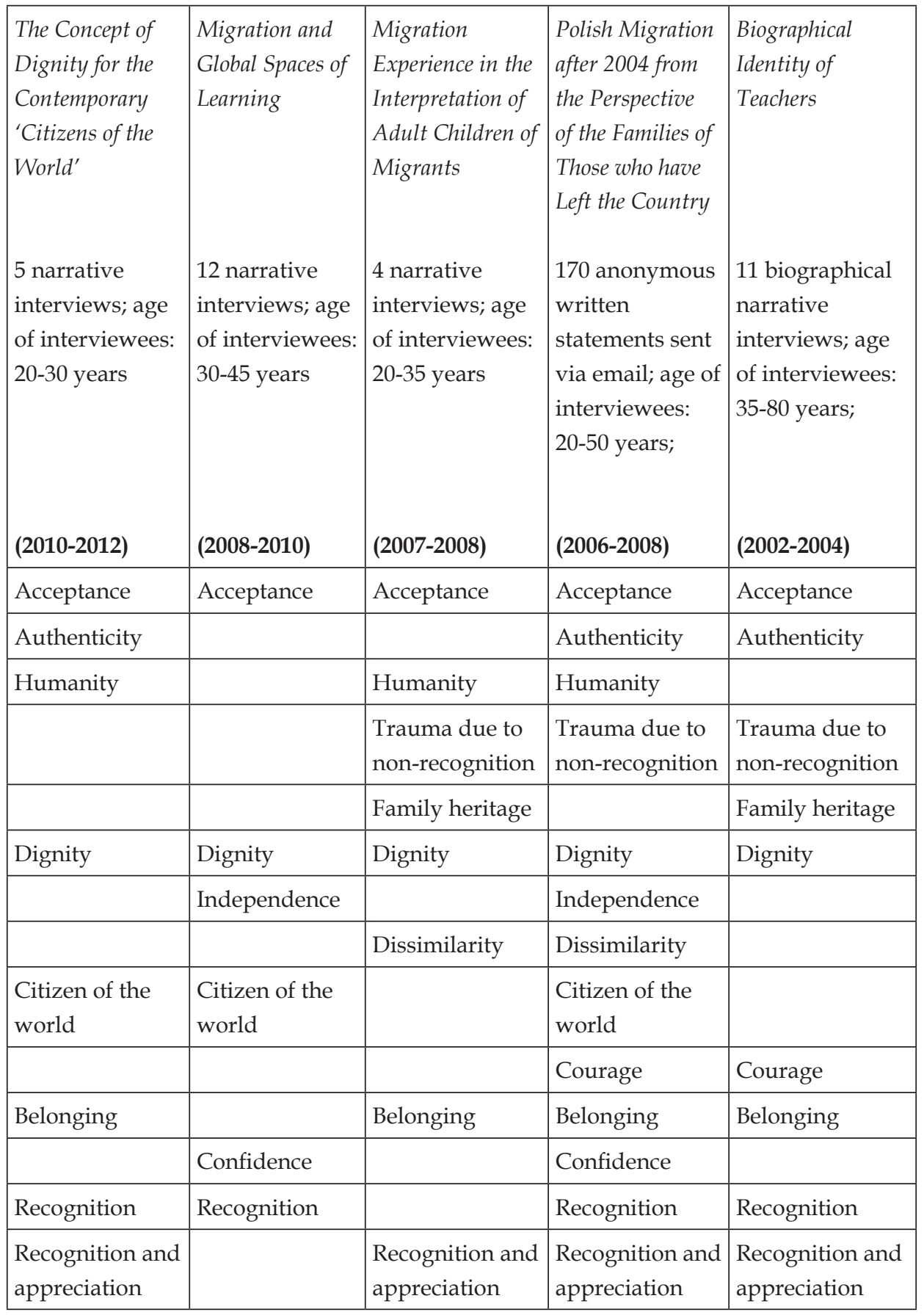




\begin{tabular}{|c|c|c|c|c|}
\hline Self-direction & Self-direction & Self-direction & & \\
\hline Self-sufficiency & & Self-sufficiency & & \\
\hline \multirow[t]{3}{*}{ Social status } & Social status & & Social status & \\
\hline & & & & $\begin{array}{l}\text { Stigmatization- } \\
\text { lack of } \\
\text { acceptance }\end{array}$ \\
\hline & Respect & & & \\
\hline Visibility & Visibility & & & Visibility \\
\hline Inclusion & & Inclusion & Inclusion & Inclusion \\
\hline Freedom & Freedom & Freedom & & \\
\hline $\begin{array}{l}\text { Sensitivity to } \\
\text { other cultures }\end{array}$ & $\begin{array}{l}\text { Sensitivity to } \\
\text { other cultures }\end{array}$ & & $\begin{array}{l}\text { Sensitivity to } \\
\text { other cultures }\end{array}$ & \\
\hline
\end{tabular}

Source: Author's own elaboration

The categories proposed by me, such as 'dignity' and 'identity,' may seem overwhelming due to their monumentality and the abundance of scientific references. At first, I felt strongly subdued by their weight. It is impossible to refer to all semantically saturated theories and concepts, all interdisciplinary discussions participated by philosophers with their moral-ethical considerations, all analyzes carried out by psychologists, anthropologists, lawyers and sociologists. Similar conclusions were probably reached by an artist presenting in a humorous way a conversation between two individuals from an undefined era (which is meant to create the impression of universality). One of the characters says, 'Ah, dignity, it is a great philosophical concept, but do you think that people are ready to understand what dignity is?' To which the second person responds, 'Will we, people, ever mature enough to fully understand what human dignity is?'

\section{Authenticity, Recognition, Visibility: Theoretical Background of the Concept of Modern Identity}

Among the many theoretical analyzes, I want to pay special attention to the concept of modern dignity by Charles Taylor, which is a response to 18th century social transformation progressing alongside the process of transition from a hierarchic society to a democratic society. This change

6 http://www.cartoonstock.com/directory/h/human_dignity [last accessed: March 20, 2012]. 
also brought about different thinking about the concept of identity. In the hierarchical society, identity was granted along with the social status and had a permanent basis. "High-born" people were automatically entitled to being honored in a unique way. They enjoyed 'respect since birth.' In the egalitarian society, respect has been replaced by modern dignity that every citizen has the right to. According to Taylor, dignity and identity have become mutually interpenetrating concepts and are inextricably related. They do not, however, exempt any person from discovering his/ her source identity, the inner 'self.' Reaching to the inner self to articulate its most indigenous authenticity is the condition of "being true to myself" (Taylor, 1994a, pp. 43-47, see also, Ricoeur, 2005). "Being true to myself means being true to my own originality, which is something only I can articulate and discover. In articulating it, I am also defining myself. I am realizing a potentiality that is properly my own. This is the background understanding to the modern ideal of authenticity, and to the goals of self-fulfillment and self-realization in which the ideal is usually couched" (Taylor, 1994a, p. 45).

In Table 1, already the first items indicate how important it is to the narrators to be authentic, accepted, recognized and socially appreciated. They point to these constructs as conditions elementary for their wellbeing, but also highlight them as the determinants of their high or low self-esteem.

Revealing oneself before oneself, but also the possibility of 'being oneself' in the public space, as indicated by Herder, are the features of originality, which for a human is always essential at both the individual and the social level (Taylor, 1994a, p. 46). This also confirms the dialogic nature of human life (Habermas, 2003). Thus, the sense of personal dignity, at the root of which there lie authenticity and identity, is dependent by its very nature on social acceptance, respect and recognition (Taylor, 1994a, p. 43). In ancient Greece, the socially constructed respect and recognition were rooted in the organization of public life. One's sense of being respected, recognized and treated with dignity, both in the private sphere and in the public one, is dependent on recognition, appreciation, acceptance and respect manifested by others. People desire dignity which they can only receive from others-through their recognition and appreciation for what they are. What makes people true to themselves is another prerequisite for the creation of modern identity. Recognition, appreciation, and authenticity are essential to the constitution of personal dignity. People who suffer from non-recognition related to what they are have lower self-esteem and feel that they belong to the second, inferior class (Taylor, 1994a, p. 46; Ricoeur, 2005, p. 83). 


\section{Universe of Obligation and Social Visibility, Transparency, Inclusion, Exclusion}

The concept of the universe of obligation, elaborated by Helen Fein (Fein, 1995, after Gamson, 1996), comprises, to cut a long story short, culturally established duties which allow to distinguish US from THEM. Given that in the social world there operate at the same time a number of different 'universes of obligation,' and each of them precisely defines how to treat the members of a particular universe as opposed to 'outsiders,' a lot of questions emerge, already old but worth being reminded: 'who am I(?), who are We(?), and who are They?' These difficult questions, however, generate further questions: 'For whom does a specific universe of obligation pose a threat of exclusion or, vice versa, is an opportunity of inclusion?' (Gamson, 1996, p 3).

Following the thought of Fein, we can assume that the social inclusion process takes place when the boundaries of the universe of obligation-the culturally defined duties-are in line with the duties of the given community. On the other hand, the universe of obligation assumes the exclusive character when one or more of the socially accepted values does/do not fit within the limits of the specified universe (Gamson, 1996, p. 6). As justified by Fein (1995), contemporary transformations of social and economic structures trigger the need to rethink the place and role of the various minority groups, including those that regard people with different types of dysfunctions and impairments. If we want to expand the boundaries of the universe, rather than enhance the processes of social exclusion, we are forced to continually broaden the array of ways of counteracting exclusion. The researcher warns that social exclusion usually starts with small steps leading to social transparency and being invisible. Social invisibility already is a soft form of exclusion, which can very quickly turn into active exclusion or hidden, indirect one (ibid.).

From the utterances of the narrators it can be gathered that being noticed (visible) is one of the first steps in the construction of their own dignity, followed by the inner desire to be true to oneself, and then the need to be seen, recognized, accepted, and eventually included into a social group, with which one can identify oneself at different levels and with different engagement (Ricoeur, 2005, p. 142). On the one hand, visibility and recognition make the inherent conditions of building one's self-esteem and constructing one's sense of dignity in the new milieu; but visibility also has its other face. 


\section{The Paradox of Being Visible}

Being socially noticed, visible, does not necessarily mean the social acceptance and consent to the inclusion or admission to the culturally established universe of obligation. Paradoxically, visibility may well lead to subtle indirect forms of exclusion, such as stigmatization and segregation, followed by active exclusion, until total genocide (Gamson, 1996, p. 10). Therefore, social sensitivity should be sharpened at the time when "transparency" becomes "visibility" (ibid.). This is a turning point in which a recognizable subject and its associated social status can take on two very different forms. The status may be elevated or lowered. When transparent members of the society become visible, surely this means that their presence is gaining significance, that they are becoming important, but such a situation does not necessarily guarantee them a sense of security. As claimed by Gamson (1996, p. 10), "It is better not to be seen at all than to be beaten, raped, or killed."

\section{'Non-migrants' versus 'Global Citizens'}

The term 'migrant,' in addition to the traditional meaning, is the carrier of information, which from the point of view of the concept of the universe of obligation questions belonging to US. Since a migrant does not belong to US, he/she does not fulfill the responsibilities valid in the universe of obligation and therefore can be threatened by exclusion. In this case, the privilege alone of being a man who has the right to equality, dignity and respect is not sufficient. These values are overridden by a set of culturally established rights and obligations of the universe, which no migrant-by definition-is able to meet. This kind of experience is documented in all 32 narrative interviews. What seems very interesting is the fact that 21 narratives out of 32 (provided by the youngest generation of narrators) contain similar, repetitive, phrases, "I am not a migrant, I am a citizen of the world," "I feel a citizen of the world" or "I do not consider myself to be a migrant, but a citizen of the world." In their further statements, the narrators argue that the concept of a 'migrant' is outdated, because it does not take into account the difference between those who emigrate voluntarily and the 'migrants of the past,' in whose case it was the political or economic coercion that dictated the terms which they had to accept. "In the EU we are not migrants. We're just like at home. It's our choice. We can simply move to a place where we can live comfortably. It's like in the past when people used to move from town to town in their own country. Now, the world has become a little wider for us"-they repeat. 
Probably none of the narrators, who today call themselves the 'citizens of the world,' knows that not only do they refer to Diogenes (413-323 BC) and his idea of a cosmopolitan world, but they often choose the same way of life as he did. This Greek cynic dared to refuse to belong exclusively to his own local world. He was poor by choice and lived in a barrel at the market, treating it like his home. He identified poverty with independence. By freedom of thought he promoted freedom of speech. He advocated as well complete independence and self-sufficiency, which was to encourage the release of the unnecessary ballast and restrictive privileges (Nussbaum, 1997, pp. 50-84). ${ }^{7}$

\section{Tourists, Vagabonds or Citizens of Two Worlds?}

Freedom, independence, and self-sufficiency are also mentioned by the narrators. I have not found descriptions which would reflect the dilemmas of modern wanderers more accurately than Bauman's metaphorical "tourists" and "vagabonds." Zygmunt Bauman perceives in them both the heroes and victims of postmodernity. According to him, they are their own alter ego (cf. Bauman, 2000, p. 94, 96). They can see themselves in their own reflections-just as in a mirror. The difference between them is, however, essential. The highest value for a tourist is mobility and the ability to wander following one's own choice. The freedom of choice and the need of roaming wide spaces are the incentives for incessant moving from one location to another. Stressing self-reliance and freedom in choosing the destination appears in numerous interviews conducted by me. Similarly to the work of the sociologist referred to above, what is most accentuated here is mobility, identified by a tourist with freedom, autonomy and independence. A tourist is convinced that his/her choices depend only on his/her decisions (ibid., p. 92). Bauman emphasizes the distance a tourist keeps towards the world in which he/she resides, agreeing to casualness, but also readily escaping from the non-benevolence of the world, seeking refuge in an imitation of an air bubble. Such person comes to the world as much as he/she must, but has the feeling of being self-sufficient.

7 According to Martha Nussbaum, Diogenes's cosmopolitanism has had an impact not only on the Western philosophical thought, but has also become a part of Hindu philosophy. A representative of Indian cosmopolitanism is, among others, Rabindranath Tagore (1861-1941), who deliberately combined the ancient Bengal philosophy with the cosmopolitanism of the West. A similar position is represented by Kwame Anthony Appiah (1954), a contemporary philosopher from Ghana, who suggests that human problems should be considered regardless of the country or continent of one's origin. In his view, the same problems apply to all people irrespective of their place of residence (Nussbaum, 1997, pp. 50-84). 
Vagabonds make a counterweight to tourists since whatever place they reach, they are unwelcome. A vagabond wanders because he/she has to protect himself/herself. His/her fate depends on the whims of the natives. However, an underappreciated strength of a vagabond is the ability to expose the false face of a tourist (ibid., pp. 94-97). A biographical trajectory of a vagabond is filled with failures and falls. In my opinion, Bauman puts forward a quite clear-cut question, "To what extent do the paths followed by tourists and vagabonds depend on their own choices?'

In the light of the meanings hidden behind the metaphors of a tourist and a vagabond it is worth considering the possibilities and strategies of constituting one's (post)modern identity in a heterogeneous world where, by choice or not, people assume the roles of tourists and/or vagabonds.

The gathered empirical materials also suggest a certain doubt, namely: 'How can we make sure that tourists and vagabonds are not the same persons?' Following blindly Bauman's division into tourists and vagabonds we can fall under the illusion that each of these groups is represented by other people. However, the narrators participating in my projects identify themselves both with tourists and vagabonds. More interestingly, they state that they use the benefit of the privileges of tourists typically outside their own country. We may risk a claim that they feel safer where the universe of obligation is strange to them, or at least less understandable than the one in their own country. Paradoxically, they feel as vagabonds every time they return to their home country. This is the beginning of their being perceived as 'They' instead of 'We'. They say about themselves: "I do not know anymore where I belong. Where is my place-more out there, or more here? I live in two worlds, and yet I am fully in neither of them"; "I do not know how long I will stay abroad. I have here a job, the family, I develop, I can afford a decent vacation and a trip to the south of Europe. The thought of returning to the country scares me. There is no work, my bonds are broken, there is virtually nothing... The worst thing is probably that neither the government of my country nor even my former neighbors-no one is waiting here for me."

Is it so, sometimes, that postmodern transformations by definition make us "citizens of two worlds" as Hans-Georg Gadamer (1992, pp. 209220) tries to remind us? He indicates that "A type of self-encounter can also occur with another and in relation on to what is different. However, the task of learning to recognize the common in another and in something different, is more pressing than ever. In our ever smaller world, cultures, religions, customs, and values of the most different variety are encountered. [...] The science of humans in their complete diversity becomes a moral and philosophical task for us all" (Gadamer, 1992, p. 220). 
I think that Gadamer's position is a delicate suggestion, which is to encourage the next generations to further development of sensitivity to other people as well as to stimulate us to use all possible means in order to build "the communicative communality" (Gadamer, 1992, p. 220). Nevertheless, the knowledge that can support comprehending the needs of a man comes from his/her real experience.

\section{Terms of the Constitution of Postmodern Identity and Dignity}

Following the path of Gadamer and summarizing the presented research results, I want to propose a continuum of meanings established on the basis of categories (extracted from the empirical material) indicated by the study participants through the sublimation of their own experiences. The categories obtained in this way form a string composed of fifteen items that can be considered as conditions essential in the constitution of postmodern identity and dignity in a heterogeneous world. The inspiration for the broadening of this continuum was a continuum consisting of six stages, characterizing social inclusion/exclusion elaborated by Helen Fein.

Table 2. Summary of A) continuum of social inclusion/exclusion by Helen Fein, B) continuum of the constitution of postmodern identity based on H. Fein and the author's own research

\begin{tabular}{|c|l|}
\hline $\begin{array}{c}\text { Continuum of social inclusion/exclusion } \\
\text { Helen Fein (1995) }\end{array}$ & $\begin{array}{c}\text { Continuum of the constitution of } \\
\text { postmodern identity based on the analysis } \\
\text { and interpretation of the empirical material }\end{array}$ \\
\hline A & B \\
\hline \multicolumn{2}{|c|}{ Positive conditions } \\
\hline Being visible and respected & Being true to myself \\
\hline & Being visible and respected \\
\hline & Recognition (appreciation) \\
\hline & Authenticity in a social group \\
\hline & Belonging \\
\hline Active participation (inclusion) & Acceptance \\
\hline & Active participation (inclusion) \\
\hline \multicolumn{2}{|l}{ Negative conditions } \\
\hline
\end{tabular}




\begin{tabular}{|l|l|}
\hline $\begin{array}{l}\text { Transparency, being invisible, } \\
\text { overlooked }\end{array}$ & $\begin{array}{l}\text { Transparency, being invisible, } \\
\text { overlooked }\end{array}$ \\
\hline & Trauma due to non-recognition \\
\hline Being visible, but stigmatized & Being visible, but stigmatized \\
\hline & Assuming false identity \\
\hline Hidden exclusion (indirect) & Discredit \\
\hline & Hidden exclusion (indirect) \\
\hline Active exclusion & Discrimination \\
\hline
\end{tabular}

Source: H. Fein (1995) and the author's own research

I marked in bold the categories distinguished by Fein and echoed by the participants of my projects. In the left column, Fein puts six stages of the transition from social exclusion to inclusion. Her scale, starting with "visibility" and ending with "active exclusion" is 'drawn apart' and supplemented with the meanings indicated by the narrators. Thus, a fifteen-grade continuum of meanings was established, going from positive to negative expressions characterizing the experiences of the participants in the projects. The continuum opens with the category of "being true to myself" (Taylor, 1994a; 1994b; Ricoeur, 2005) and ends-as proposed by Fein-with the total (active) exclusion, which in the interpretation of the narrators becomes a blockade hampering the constitution of their identity and which, while discrediting them, triggers the feeling of being secondclass man (Taylor, 1994a).

The right part of the table contains a richer list of 'conditions' referred to by the narrators as regards giving them a sense of security in the process of constituting their identity while maintaining personal dignity. Thus, the narrators point to delicacy and sensitivity of their feelings in the social world, in which they come to face daily the current universe of obligation.

\section{References}

Bauman, Z. (2000). Globalization: The Human Consequences. Cambridge, UK: Polity Press.

Castles, S., \& Miller, M.I. (1993). The Age of Migration: International Population Movements in the Modern World. London: Macmillan. 
Collins World English Dictionary, http://dictionary.reference.com/browse/migrant [last accessed: January 20, 2012].

Fein, H. (1995). Accounting for Genocide after 1945: Theories and Some Findings. International Journal on Group Rights, 1, 79-106.

Gadamer, H-G. (1992). Citizens of Two Worlds. In H-G. Gadamer, Hans-Georg Gadamer on Education, Poetry, and History: Applied Hermeneutics (pp. 209-220). (D. Misgeld \& G. Nicolson, Eds.; L. Schmidt \& M. Reuss, Trans.). New York: State University of New York Press.

Gamson, W.A. (1995). Hiroshima, the Holocaust, and the Politics of Exclusion: 1994 Presidential Address. American Sociological Review, 60 (1), 1-20.

Goffman, E. (1963). Stigma: Notes on the Management of Spoiled Identity. New York: Simon and Schuster.

Habermas, J. (2003). The Future of Human Nature. (W. Rehg, M. Pensky, \& H. Beister, Trans.) Cambidge, UK: Polity Press.

Halbwachs, M. (1992). On Collective Memory. (L.A. Coser, Ed., Trans.). Chicago London: University of Chicago Press.

Jackson, S. (1995). Patchwork Girl. Eastgaste Systems - CD-ROM ed.

Jaksa Bykowski, P. (1884). Dwór Królewski w Grodnie: Epizod biograficzny 17951797, http:/ / www.pbi.edu.pl/book_reader.php?p=33215\&s=1 [last accessed: March 3, 2012].

Kaźmierska, K. (1999). Doświadczenia wojenne Polaków a kształtowanie tożsamości etnicznej: Analiza narracji kresowych. Warszawa: Wydawnictwo Instytutu Filozofii i Socjologii Polskiej Akademii Nauk.

Kozak, S. (2010). Patologia eurosieroctwa w Polsce. Warszawa: Difin.

Ligus, R. (2011a). Migration and Global Learning Spaces. In A. Fragoso, E. Kurantowicz, \& E. Lucio-Villegas (Eds.), Between Global and Local: Adult Learning and Development (pp. 191-204). Frankfurt am Mein: Peter Lang.

Ligus, R. (2011b). Adult Children of Emigrants and Their Migration Experience. In S. Egger \& J. McDonagh (Eds.), Polish-Irish Encounters in the Old and New Europe. Series: Reimagining Ireland, Vol. 39 (pp. 215-229). Bern: Peter Lang.

Ligus, R. (2009). Biograficzna tożsamość nauczycieli. Wrocław: Dolnośląska Szkoła Wyższa we Wrocławiu.

Nussbaum, M.C. (1997). Cultivating Humanity: A Classical Defence of Reform in Liberal Education. Cambridge, MA: Harvard University Press. 
Polkinghorne, D.E. (2005/1995). Narrative Configuration in Qualitative Analysis, In J. Amos Hatch \& R. Wisniewski (Eds.), Life history and Narrative. Qualitative Series Studies, Vol. 1 (pp. 5-23). London - New York: Falmer Press.

Ricoeur, P. (2005). The Course of Recognition. (D. Pellauer, Trans.). Cambridge, MA: Harvard University Press.

Schütze, F. (1983). Biographieforschung und narratives Interview, Neue Praxis, 13 (3), 283-293.

Stake, R.E. (2005). Qualitative Case Studies. In N.K. Denzin \& Y.S. Lincoln (Eds.), Handbook of Qualitative Research. 3rd ed. (pp. 443-466). London - Thousand Oaks - New Delhi: Sage.

Taylor, C. (1994a). Multiculturalism and the Politics of Recognition. In A. Gutmann (Ed.), Multiculturalism, Examining the Politics of Recognition (pp. 40-90). Princeton, NY: Princeton University Press.

Taylor, C. (1994b). Sources of the Self: The Making of the Modern Identity. Cambridge, MA: Harvard University Press. 